\title{
Transorbital endoscopic eyelid approach for resection of sphenoorbital meningiomas with predominant hyperostosis: report of 2 cases
}

\author{
João Paulo Almeida, MD, ${ }^{1}$ Sacit B. Omay, MD, ${ }^{1}$ Sathwik R. Shetty, MD, ${ }^{1}$ Yu-Ning Chen, MD, ${ }^{1}$ \\ Armando S. Ruiz-Treviño, MD, ${ }^{1}$ Buqing Liang, MD, ${ }^{1}$ Vijay K. Anand, MD, ${ }^{2}$ Benjamin Levine, MD, ${ }^{3}$ \\ and Theodore H. Schwartz, MD1,2
}

Departments of ${ }^{1}$ Neurological Surgery, ${ }^{2}$ Otolaryngology, and ${ }^{3}$ Ophthalmology, Weill Cornell Medical College, NewYork-Presbyterian Hospital, New York, New York

Sphenoorbital meningiomas (SOMs) are slow-growing tumors that originate from the sphenoidal wing and are associated with visual deterioration, extrinsic ocular movement disorders, and proptosis caused by hyperostosis of the lateral wall of the orbit. In some cases, the intracranial component is quite small or "en plaque," and the majority of the symptoms arise from adjacent hyperostosis. Craniotomy has traditionally been the standard of care, but new minimally invasive multiportal endoscopic approaches offer an alternative. In the current study, the authors to present their experience with the transorbital endoscopic eyelid approach for the treatment of 2 patients with SOMs and sphenoid wing hyperostosis.

Clinical and radiological data for patients with SOMs who underwent a transorbital endoscopic eyelid approach were retrospectively reviewed. Surgical technique and clinical and radiographic outcomes were analyzed.

The authors report the cases of 2 patients with SOMs and proptosis due to sphenoid wing hyperostosis. One patient underwent prior craniotomy to debulk the intracranial portion of the tumor, and the other had a minimal intracranial component. Both patients were discharged 2 days after surgery. MR images and CT scans demonstrated a large debulking of the hyperostotic bone. Postoperative measurement of the proptosis with the aid of an exophthalmometer demonstrated significant reduction of the proptosis in one of the cases. Persistence of intraconal tumor in the orbital apex limited the efficacy of the procedure in the other case. A review of the literature revealed 1 publication with 3 reports of the transorbital eyelid approach for SOMs. No measure of relief of proptosis after this surgery had been previously reported.

The transorbital endoscopic approach, combined with endonasal decompression of the medial orbit, may be a useful minimally invasive alternative to craniotomy in a subset of SOMs with a predominantly hyperostotic orbital wall and minimal intracranial bulky or merely en plaque disease. In these cases, relief of proptosis and optic nerve compression are the primary goals of surgery, rather than gross-total resection, which may have high morbidity or be unachievable. In cases with significant residual intraconal tumor, orbital bone removal alone may not be sufficient to reduce proptosis.

https://thejns.org/doi/abs/10.3171/2017.3.JNS163110

KEY WORDS transorbital; endoscopy; sphenoorbital meningioma; endonasal; skull base; surgical technique

$\mathrm{S}$ PHENOORBITAL meningiomas (SOMs) are slow-growing tumors that originate from the dura surrounding the sphenoid wing. They account for approximately $9 \%$ of all intracranial meningiomas ${ }^{12,37}$ and may present as "en plaque" tumors, usually associated with hyperostosis, intraosseous tumor growth, and soft-tissue growth adherent to the dura. ${ }^{25,26,37,43}$ Progressive enlargement of those tumors is followed by compression of surrounding structures, such as the orbit, superior orbital fissure, optic canal, and cavernous sinus, which may lead to visual deterioration, disturbance of ocular movements, proptosis, and cosmetic alterations. ${ }^{25,43}$

Resection with functional preservation is the main treatment option for SOMs. Different skull base approaches may be used for excision of those lesions, including the pterional, orbitozygomatic, and subfrontal approaches. However, gross-total resection, with removal of the affected dura and drilling of the hyperostotic bone, might

ABBREVIATIONS SOM = sphenoorbital meningioma.

SUBMITTED December 10, 2016. ACCEPTED March 23, 2017.

INCLUDE WHEN CITING Published online September 1, 2017; DOI: 10.3171/2017.3.JNS163110. 
not be safely achieved in more than $50 \%$ of patients. ${ }^{29,43,46}$ Therefore, residual tumor and recurrence are not uncommon, and reoperation and adjuvant radiotherapy play important roles in the management of these lesions. ${ }^{38,40,43,46,49}$ Moreover, in patients with a predominantly hyperostotic orbital wall and minimal intradural disease, an extradural approach would be favored.

In the past few decades, the evolution of minimally invasive techniques has contributed to the development of new approaches to the skull base. Currently, endoscopic endonasal approaches are validated options for resection of midline tumors, from the cribriform plate to the craniovertebral junction, including lesions at the medial and inferior portion of the orbit and inferomedial components of SOMs that may enter into the infratemporal fossa and lateral sphenoid sinus. ${ }^{13-15,39,50,52}$ However, resection of lateral skull base lesions, such as lateral sphenoid meningiomas, remains one of the major limitations of the endoscopic endonasal approach. Recently, a multiportal transorbital and endonasal approach has been proposed as a new minimally invasive option to reach the lateral orbit and middle fossa. ${ }^{20,22,41}$ These approaches are particularly suited for patients with predominant hyperostosis and minimal intracranial or "en plaque" disease in whom relief of proptosis and optic canal compression are the primary goals of surgery. Here, we report the cases of 2 patients with SOMs that were treated via a combined transorbital and endonasal endoscopic approach, and we discuss the advantages, disadvantages, and indications for this approach in the context of a review of the published literature on the topic.

\section{Methods}

Clinical and radiological data for patients who had undergone a transorbital endoscopic eyelid approach were retrospectively reviewed. Surgical technique and clinical and radiographic outcomes were analyzed. In this paper, we present surgical videos and illustrations to demonstrate the nuances of the approach. A retrospective review of the literature regarding multiportal approaches for skull base lesions was performed to illustrate the clinical applications of the technique in recent years.

\section{Case Reports}

\section{Case 1}

A 53-year-old woman who had undergone a craniotomy for resection of an SOM (Grade I) at an outside institution 3 years earlier presented with a 2-month history of visual deterioration and progressive proptosis. The patient's clinical examination revealed right-sided proptosis, visual field testing revealed a developing superolateral quadrant scotoma in the right eye, and visual acuity according to the Snellen Eye Test was symmetrical (20/25 in both eyes). MR images and CT scans revealed a partially resected right-sided SOM, with significant hyperostosis at the orbital roof, lateral wall, and greater sphenoidal wing, narrowing of the superior orbital fissure and optic canal, and right eye proptosis (Fig. 1). Preoperatively, $3.5 \mathrm{~mm}$ of proptosis was measured on the axial MR image, and the oculoplastic surgeon graded the patient's proptosis as $3+$.
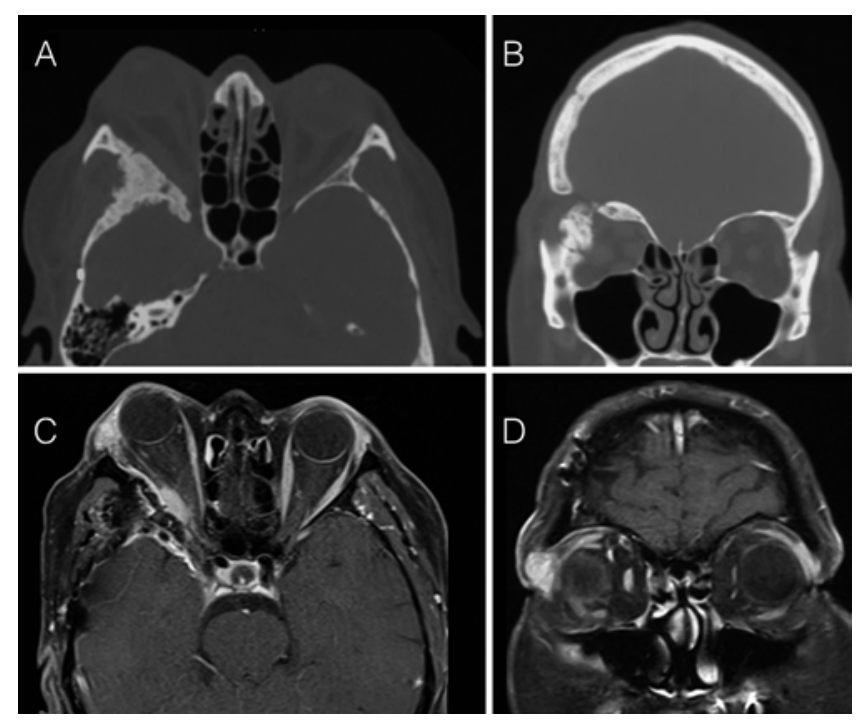

FIG. 1. Case 1. Preoperative images. A and B: Axial $(A)$ and coronal (B) CT scans demonstrating extensive hyperostosis centered within the right sphenoid involving the greater and lesser right sphenoid wings as well as the orbital, frontal, and zygoma bones. There is increased bone formation and mineralization in this region likely from hyperostosis due to a known meningioma. C and D: Preoperative axial (C) and coronal (D) MR images showing tumor that is compatible with meningioma in the right orbit and superior orbital fissure, and extending intracranially over the right greater wing into the right middle fossa.

Considering the history of a previous unsuccessful transcranial approach, the location of the lesion, and the diagnosis of a Grade I meningioma, we elected to proceed with a combined endoscopic transorbital and endonasal approach for resection of the hyperostotic bone and orbital decompression.

The operation involved collaboration of neurosurgery, ENT, and oculoplastic surgery (Video 1).

VIDEO 1. Case 1. Surgical video demonstrating the technique for combined endoscopic transorbital and endonasal management of SOMs. Copyright Weill Cornell Medical College, NewYorkPresbyterian Hospital. Published with permission. Click here to view.

After induction of general anesthesia, the patient was placed supine, and her head was fixed after gentle elevation with a Mayfield head holder. A sterile protective corneal shield lubricated with ophthalmic ointment was placed in the right eye. The initial part of the procedure consisted of the endoscopic endonasal approach. As previously described, an endonasal approach to the medial orbit was performed, the lamina papyracea was removed, and the medial optic canal was decompressed (Fig. 2). Removal of the lamina papyracea helped to mobilize the globe medially during the transorbital approach and the decompression of the medical optic canal helped to decompress the optic nerve.

A superior eyelid approach was then performed. The orbicularis layer was opened along the length of the incision to expose the periosteum of the lateral orbital rim. The periorbita was elevated along the inner aspect of the lateral orbital rim using a freer elevator. The orbit was 


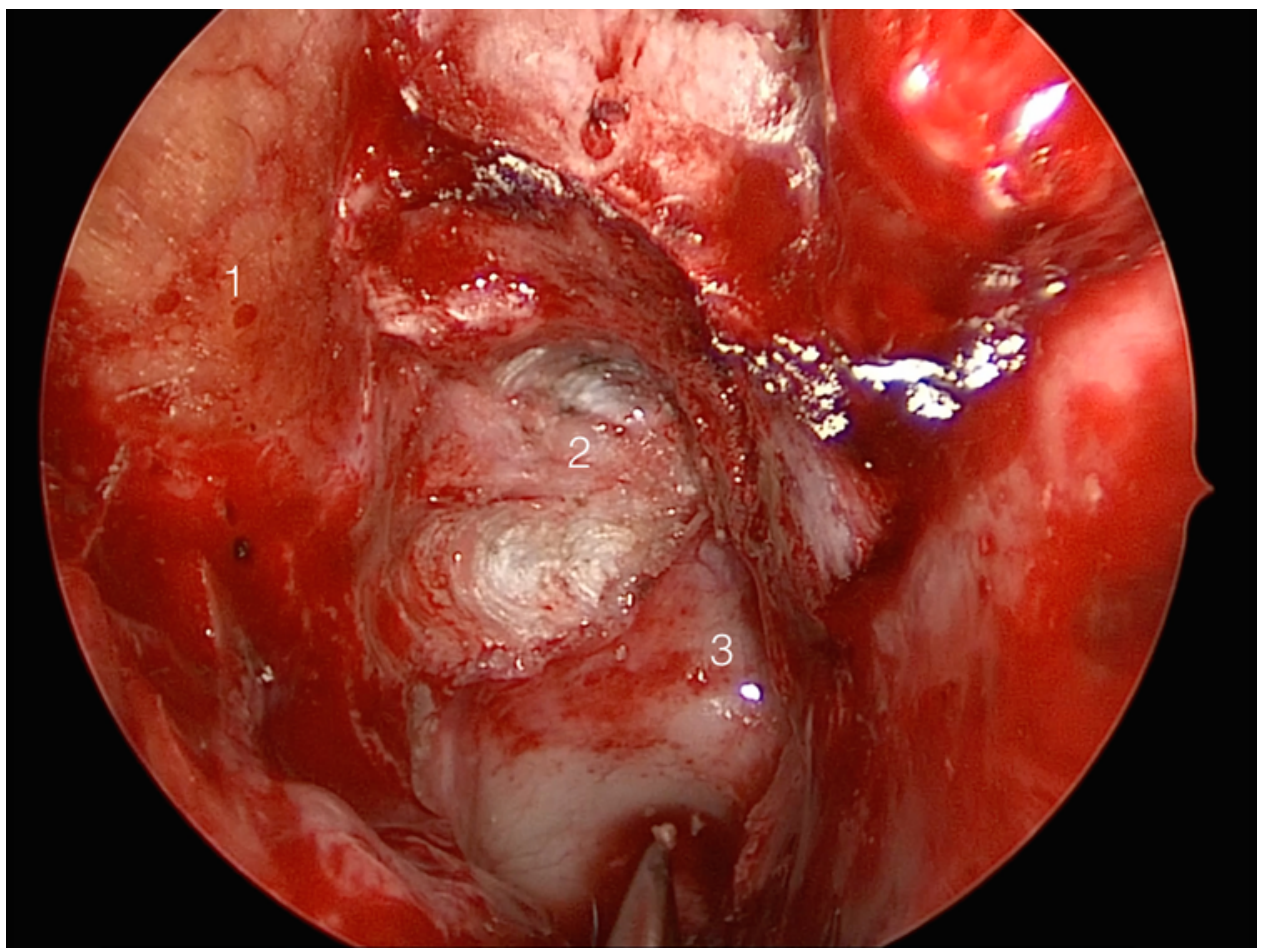

FIG. 2. Case 1. Endoscopic endonasal exposure after medioinferior orbital decompression. The lamina papyracea (1) was removed, exposing the medial orbit, and the optic canal (2) was drilled and decompressed. The sphenoid sinus is also observed (3). Figure is available in color online only.

protected by a silastic sheet. The hyperostotic bone of the orbit was exposed along the lateral orbit posteriorly to the level of the superior orbital fissure and superiorly under the anterior cranial fossa. CT image guidance was used to aid in identifying the orbital landmarks. Once adequate exposure was obtained, decompression of the hyperostotic bone and tumor removal were done using highspeed drills and Kerrison rongeurs (Fig. 3). The medial landmarks were the superior and inferior orbital fissures (Fig. 4). At the end of the procedure, a dural defect with a small CSF leak was seen in the supraorbital region. A fat graft was harvested from the central preaponeurotic fat pad of the upper lid (Fig. 5). The fat graft was then placed over the area of dural exposure and secured in place using Tisseel glue (Baxter). After the transorbital and endonasal approaches, a lateral canthal dystopia, secondary to the disease process, was additionally corrected. The eyelid incision was closed using interrupted 6-0 nylon sutures. Erythromycin ophthalmic ointment was applied the surgical site and to the left eye.

The patient was discharged 2 days after surgery, with subjective improvement in her vision and no complications. MR images and CT scans demonstrated a significant debulking of the hyperostotic bone (Fig. 6). At the 1-month postoperative surgical evaluation, the patient exhibited improvement of proptosis to 1+ and improvement in her visual symptoms. Visual field evaluation demonstrated a partial improvement in the preoperative superolaterally localized deficit, and the patient's visual acuity was stable after surgery (20/25 in both eyes). At
3 months, MRI showed remaining soft tissue, consistent with intraconal tumor in the orbital apex, and no further improvement of the proptosis. The final pathology result was compatible with a Grade I meningioma. The patient was referred to the radiosurgery service for control of the residual intradural tumor.

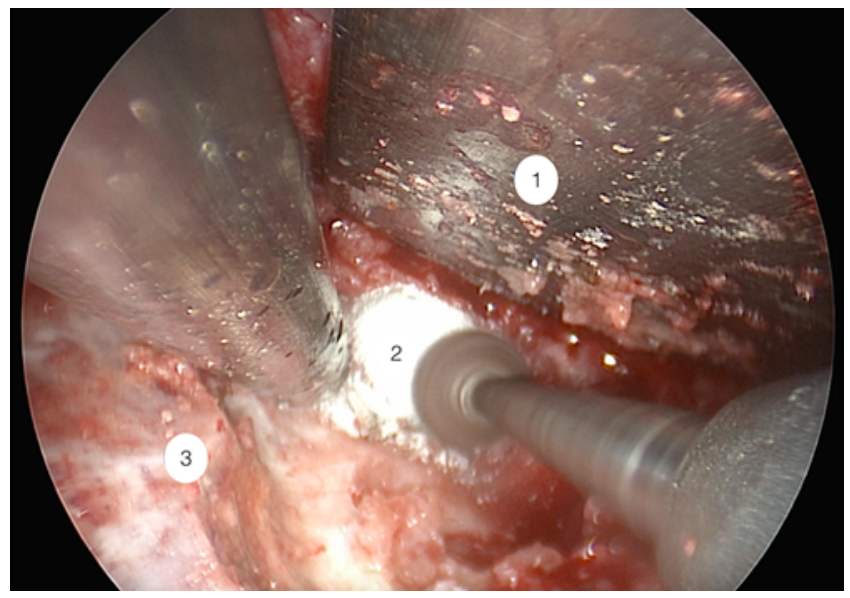

FIG. 3. Case 1. Transorbital endoscopic drilling of the hyperostotic bone at the greater sphenoidal wing and orbital roof. This intraoperative view shows the spatula over the orbital contents to improve the surgical exposure of the orbital roof and lateral wall of the orbit (1), drilling over the greater sphenoidal wing (2), and orbital roof (3). Figure is available in color online only. 

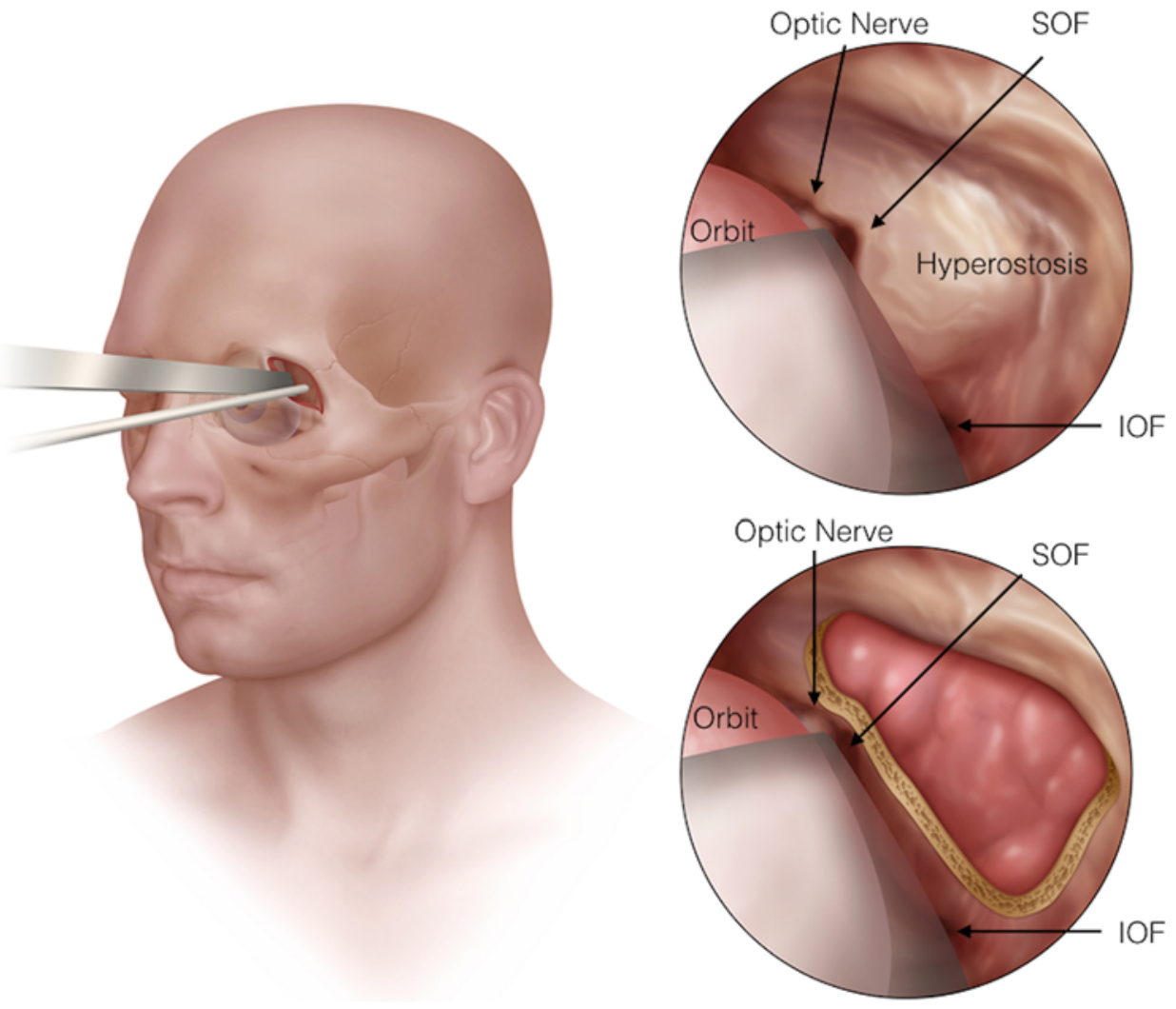

FIG. 4. Illustration demonstrating the transorbital endoscopic technique for treatment of SOMs. The hyperostotic bone over the orbital roof and lateral wall of the orbit, between the superior orbital and inferior orbital fissures, is removed after extensive drilling. Copyright Weill Cornell Medical College, NewYork-Presbyterian Hospital. Published with permission. Figure is available in color online only.

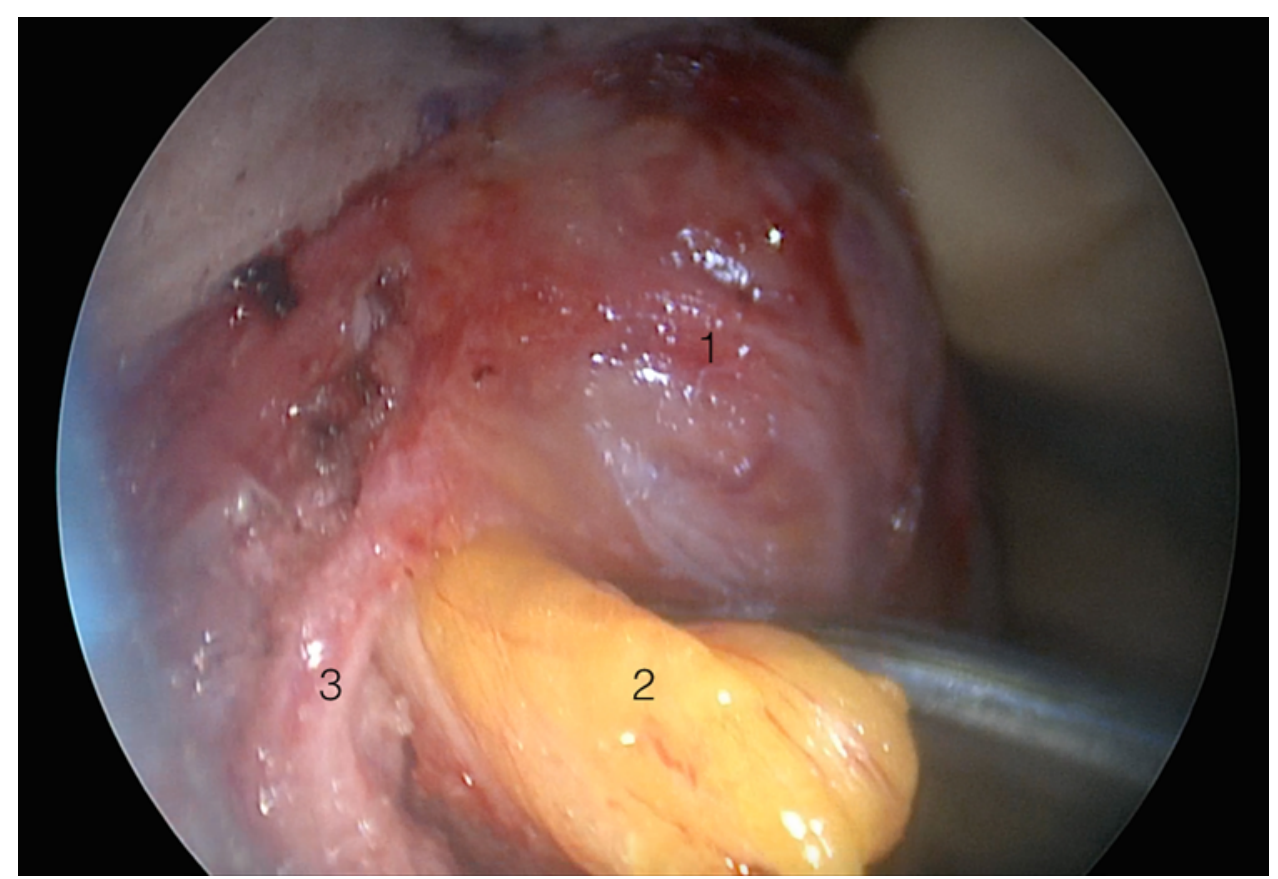

FIG. 5. Case 1. Extraction of a fat graft from the central pre-aponeurotic fat pad of the upper eyelid. The orbital contents (1), fat graft (2), and orbital roof (3) are shown. Figure is available in color online only. 

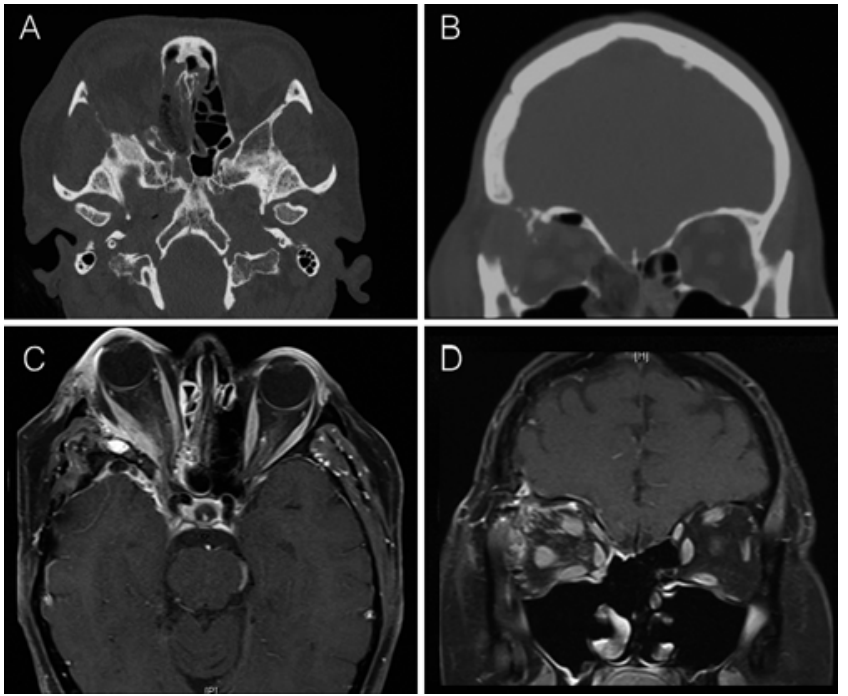

FIG. 6. Case 1. Postoperative images. A and B: Axial (A) and coronal (B) CT scans showing significant interval reduction of multiple areas of previously noted hyperostotic bone, particularly along the lateral wall and orbital roof. C and D: Postoperative axial (C) and coronal (D) MR images demonstrating extensive debulking of the lesion, with residual disease near the orbital apex.

\section{Case 2}

A 65-year-old woman presented with proptosis diagnosed by her ophthalmologist 1 month prior to presentation, at which point she recalled symptom progression over the course of 5 years. The patient's examination revealed left facial numbness and left eye proptosis, with visual testing showing 20/40 in the right eye and 20/50 in the left eye but no deterioration of visual fields or ocular movements. Preoperative evaluation of the proptosis with the aid of a Hertel exophthalmometer revealed a measurement of $21 \mathrm{~mm}$ in the left eye and $18 \mathrm{~mm}$ in the right eye. CT scanning revealed an irregular sclerotic mass involving the left greater wing of the sphenoid with associated hyperostosis around the optic canal, superior orbital fissure, and middle fossa, and regional mass effect on the left lateral rectus muscle and optic nerve (Fig. 7). MRI demonstrated an enhancing lesion suggestive of an en plaque meningioma within the orbit and anterior part of the left middle fossa that was associated with hyperostosis, causing proptosis and compression of structures at the orbital apex (Fig. 7). The patient underwent a combined endoscopic transorbital and endonasal procedure, as described in Case 1, without complications (Fig. 8 and Video 2).

VIDEO 2. Case 2. Video demonstrating the surgical technique for transorbital endoscopic decompression applied in Case 2. Copyright Weill Cornell Medical College, NewYork-Presbyterian Hospital. Published with permission. Click here to view.

Postoperative CT and MRI showed extensive bone debulking with decompression of the superior orbital fissure (Figs. 9 and 10). The patient was discharge 2 days after surgery, without complications. Pathological examination revealed a Grade I meningioma.

At early follow-up consult with ophthalmology (postoperative Day 6), the patient was still experiencing left
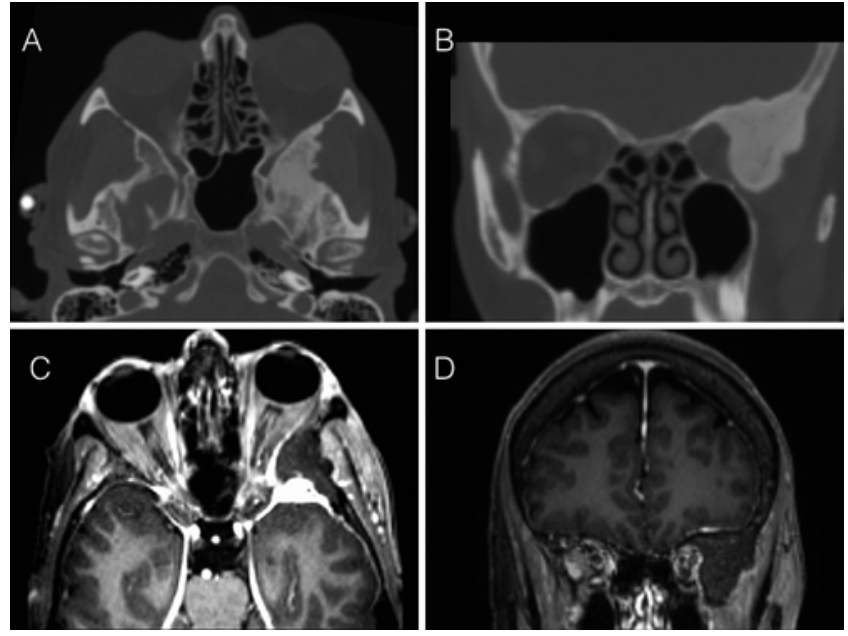

FIG. 7. Case 2. Preoperative studies. A and B: Axial (A) and coronal (B) CT scans showing a significant hyperostosis at the greater sphenoidal wing and roof of the orbit. C and D: Axial (C) and coronal (D) MR images demonstrating an en plaque meningioma in the anterior portion of the left middle fossa with intraorbital extension.

postoperative ptosis and swelling. Visual fields and intrinsic ocular movements were fully preserved after surgery. Postoperative visual acuity results (left eye 20/40) showed a partial improvement when compared with the preoperative status (left eye 20/50). One month later, a 3-mm improvement of the proptosis in the left eye was noted, and her eyes were symmetric. As in Case 1, the pathological result was compatible with a Grade I meningioma, and the patient was referred to the radiosurgery service for treatment of the residual intradural component of the tumor.

\section{Discussion}

In this report, we demonstrate the utility of the transorbital endoscopic approach to relieve proptosis caused by SOM-associated hyperostosis of the lateral orbital wall. This approach is suited for cases in which there is limited intracranial disease that does not require significant intracranial debulking. Resection of en plaque meningiomas of the skull base can cause significant morbidity, and complete resection is often unattainable. Progressive growth is manageable with fractionated radiation therapy, but relief of proptosis and optic nerve decompression requires surgery. In situations in which proptosis and visual deficits are the main symptoms, transorbital decompression may be adequate. Unroofing of the optic nerve is aided by the associated endonasal surgery, which can also serve to remove the lamina papyracea and facilitate medial retraction of the globe.

The evolution of minimally invasive techniques and, especially, endoscopic endonasal surgery, has changed the management of skull base lesions over the last 15 years. Endoscopic endonasal approaches have become a useful option for the management of midline skull base tumors, with improved rates of resection and complications compared with open approaches in well-selected cases. . $^{13,14,32}$ Lesions located in the lateral aspect of the coronal plane 


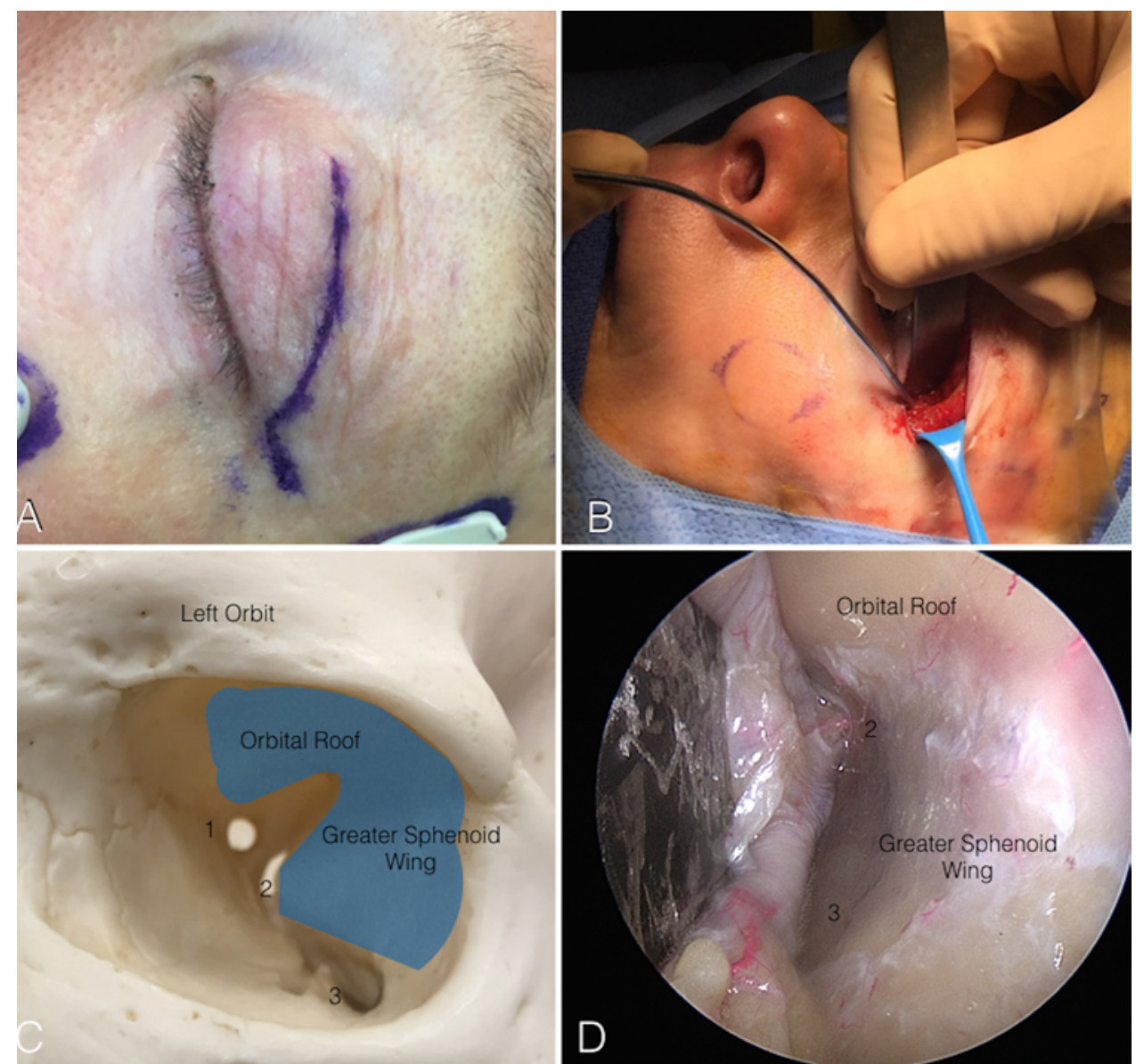

FIG. 8. Case 2. Transorbital endoscopic approach. A: A superior eyelid incision is marked from the mid aspect of the superior eyelid to the level of the lateral canthus. B: The orbital contents are retracted medially to expose the roof and posterior wall of the orbit. C and D: Anatomical images demonstrating the orbital roof, greater sphenoidal wing, optic canal (1), superior orbital fissure (2), and inferior orbital fissure (3). Drilling should be directed at the orbital roof and sphenoidal wing with preservation of the orbital fissures and their contents. Figure is available in color online only.

remain generally not amenable to a minimally invasive or minimal access approach. The lateral limits of the endonasal approaches are restricted by the presence of the
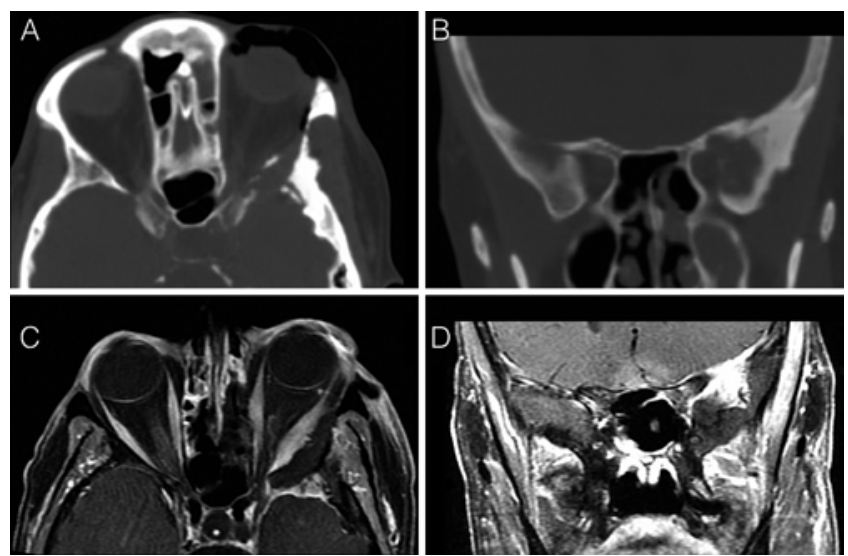

FIG. 9. Case 2. CT scans ( $A$ and $B$ ) and MR images ( $C$ and $\mathbf{D})$ demonstrating significant debulking of the hyperostotic lesion and orbital decompression. orbits, optic nerve, and superior orbital fissure. ${ }^{32}$ Therefore, lesions located lateral to those structures are generally reached via a craniotomy, such as the orbitozigomatic, pterional, or supraorbital approach. ${ }^{20}$ Classic transcranial approaches have the advantage of a wide lateral exposure, but they may be associated with postoperative functional and cosmetic sequelae. Hence, new minimally invasive approaches have been proposed to resect lateral anterior cranial fossa lesions. ${ }^{4,5,31,41}$

The concept of surgical approaches through and around the orbit is not new. The field of ophthalmology initially led the development of the "pure" transorbital or orbitotomy approaches. The concept of an anterior orbitotomy was devised by Knapp in 1874 and popularized by Benedict., ${ }^{718}$ This approach, initially designed for resection of lesions in the anterior two-thirds of the orbit, may be performed through a superior (superior eyelid or eyebrow) or inferior (transconjunctival or inferior eyelid) incision. In 1889 , the lateral orbitotomy was originally described by Kronlein and later modified by Berke. ${ }^{8}$ In 1976, Maroon and Kennerdell revolutionized the transorbital approach, with the introduction of the surgical microscope, development of new dissection tools, and use of self-retractors in 


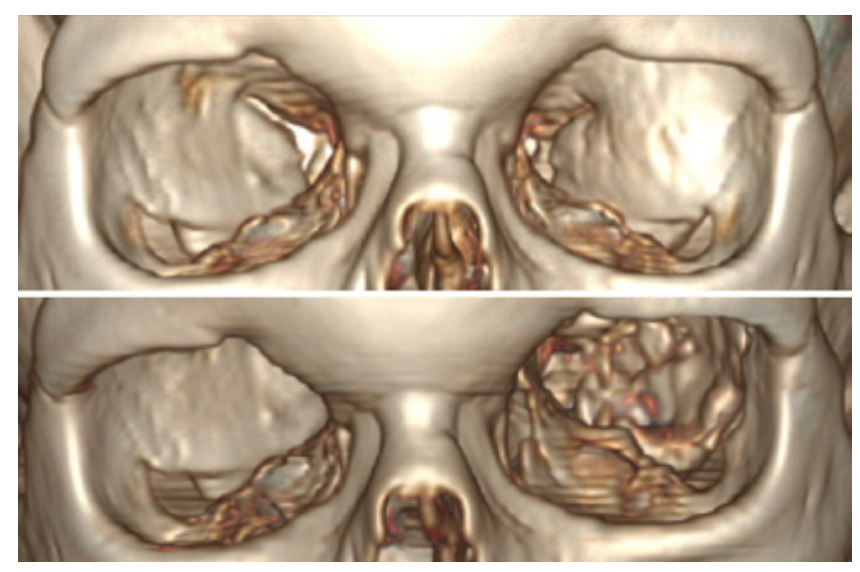

FIG. 10. Case 2. Upper: Preoperative 3D reconstructed CT scan showing the hypersostosis at the right greater sphenoid wing and orbital roof. Lower: Postoperative 3D CT scan demonstrating the large decompression of the hyperostotic bone achieved after endoscopic transorbital surgery. Figure is available in color online only.

a modified microsurgical lateral orbitotomy. ${ }^{33,36}$ Through a lateral upper brow incision and removal of the lateral and posterior walls of the orbit, selected retrobulbar and skull base lesions may be safely resected through this approach. Designed for optic nerve decompression and also applied for resection of anterior and medial intraconal lesions, the transconjunctival medial orbitotomy approach was initially described in 1973 by Galbraith and Sullivan. ${ }^{27}$

Neurosurgical approaches through the orbital roof were developed in answer to the limited exposure of most of the anterior fossa due to the orbits as well as the thinness of orbital rim. In 1913, Frazier described the orbital roof craniotomy technique, ${ }^{24}$ which allowed surgical access to the orbital contents via the lateral wall and roof of the orbit, through a modification of Dandy's original frontolateral craniotomy. To improve the access to the anterior skull base, several authors modified this technique in the following years. Classic techniques include the pterional approach as described by Yaşargil et al. ${ }^{54}$ the supraorbital approach by Jane et al., ${ }^{30}$ and the orbitozigomatic approach by Hakuba et al. ${ }^{28}$

More recently, minimally invasive microsurgical ap- proaches to the orbit and anterior skull base have been proposed, including the modified orbital roof craniotomy via an eyebrow incision, as described by Jho, ${ }^{31}$ and orbital roof craniotomy via eyelid approaches. ${ }^{1,5,42,45}$ In all different approaches, the addition of the orbital osteotomy has proven effective in decreasing brain retraction and improving the surgical exposure. . $, 5,19,23,31,45$ Lew et al. reported their success with the transorbital microsurgical approach without craniotomy for resection of orbitocranial lesions ${ }^{35}$ In that study, 9 SOMs were treated via an eyelid approach, with complete or partial correction of orbital hyperostosis and improvement of proptosis. Only 2 patients in the series had tumor recurrence during follow-up and required reoperation via a transcranial approach.

Pure transorbital endoscopic approaches to the skull base were first proposed by Moe et al. in 2010. ${ }^{41}$ Without the need for large skin incisions or removal of the orbital rim and frontal bone, this might be considered the first description of a "true" transorbital endoscopic approach..$^{53}$ As proposed by the authors, the orbit may be divided into 4 different quadrants, each with its specific approach: medial (precaruncular approach), superior (superior eyelid approach), lateral (lateral retrocanthal approach), and inferior (preseptal lower eyelid). Medial approaches were proposed to access the superior orbital fissure and optic nerve, superior approaches to the anterior cranial fossa, lateral approaches to the middle cranial fossa and infratemporal fossa, and inferior approaches to the orbital floor. ${ }^{11,41}$ This group reported the use of transorbital neuroendoscopic surgery in 16 patients. Although 14 patients (88\% of the cases) underwent surgery for CSF leaks and skull base trauma repair, a recurrent adenoid cyst resection and an infraorbital nerve biopsy were also performed via this approach. ${ }^{41}$ Regarding complications, 1 patient developed a mild unilateral enophthalmos after surgery; no major complication or postoperative neurological deficits was reported.

Cadaver dissection studies have demonstrated the utility of these approaches to reach the lateral cavernous sinus ${ }^{11}$ and mesial temporal lobe. ${ }^{16}$ Additional clinical series published by Dallan et al. ${ }^{21,22}$ and Rivkin et al. ${ }^{47}$ mostly focused on intraorbital pathology (Table 1). Ramakrishna et al. ${ }^{44}$ in a follow-up of the original study by Moe et al., ${ }^{41}$ reported the use of transorbital endoscopic surgery in 45

TABLE 1. Pure transorbital endoscopic studies

\begin{tabular}{|c|c|c|c|c|}
\hline Authors \& Year & $\begin{array}{l}\text { No. of } \\
\text { Patients }\end{array}$ & Indications & Effectiveness & Safety \\
\hline Moe et al., 2010 & 20 & $\begin{array}{l}\text { CSF leaks, skull base fracture, tumor, optic } \\
\text { nerve decompression }\end{array}$ & $\begin{array}{l}\text { Improvement of symptoms in } \\
\text { all; all CSF leaks resolved }\end{array}$ & 1 postop enophthalmia \\
\hline Dallan et al., $2015^{22}$ & 1 & Superior orbital fissure, cavernous hemangioma & Total tumor resection & Transient partial CN III palsy \\
\hline Rivkin et al., 2013 & 1 & $\begin{array}{l}\text { Posterior lacrimal gland tumor, pleomorphic } \\
\text { adenoma }\end{array}$ & Total tumor resection & No significant complications \\
\hline $\begin{array}{l}\text { Ramakrishna et al., } \\
\text { 2016* }\end{array}$ & 27 & $\begin{array}{l}\text { CSF leaks, skull base fracture, tumor, infection, } \\
\text { meningoencephalocele }\end{array}$ & Op goal achieved in all cases & $\begin{array}{l}3 \text { persistent complications: enoph- } \\
\text { thalmos, ptosis, \& epiphora }\end{array}$ \\
\hline
\end{tabular}


TABLE 2. Multiportal transorbital endonasal endoscopic approach for resection of skull base tumors

\begin{tabular}{cclll}
\hline Authors \& Year & No. of Patients & \multicolumn{1}{c}{ Indications (no.) } & Effectiveness (no.) & \multicolumn{1}{c}{ Safety } \\
\hline Dallan et al., 201520 & \multirow{2}{*}{4} & Malignant V2 schwannoma (1); & GTR; & No significant complications \\
& & SOM (3) & GTR (1); STR (2) & No significant complications \\
\hline Ramakrishna et al., & 5 & Esthesioneuroblastoma & STR & STR \\
$2016^{*}$ & & Cystic adenocarcinoma & GTR & Ethmoidal squamous cell carcinoma \\
& & Sinonasal melanoma & GTR & No significant complications \\
\hline
\end{tabular}

GTR = gross-total resection; STR = subtotal resection.

* The complete series reported by the authors include 45 cases. The cases patients not included here underwent a pure transorbital endonasal endoscopic approach.

patients with different pathologies (CSF leaks, tumor/inflammation, trauma, meningoencephalocele, and hematomas), including 11 tumor/inflammation cases.

The combination of lateral and medial corridor exposure provided by the endoscopic transorbital and endoscopic endonasal approaches, respectively, has been shown to improve the exposure of anterior and middle fossa contents in anatomical studies. ${ }^{3,17,20}$ However, reports of clinical application of the multiportal technique remain scarce. ${ }^{20,34,44,48}$ To our knowledge, only 2 papers have been published regarding its application for resection of skull base tumors..$^{20,44}$ The largest is the recently published study by Ramakrishna et al., ${ }^{44}$ who reported the use of a multiportal approach in 18 cases, including 5 skull base tumors, followed by Dallan et al., ${ }^{20}$ who reported the results of multiportal transorbital and endonasal endoscopic surgery for the treatment of 1 malignant schwannoma and 3 SOMs, with no complications (Table 2).

SOMs have a growth pattern that makes them good candidates for a combined endoscopic transorbital and endonasal approaches. They may extend from the greater wing of the sphenoid into the lateral and medial aspects of the superior orbital fissure and, in $8 \%-12 \%$ of the cases, they run into the pterygopalatine and infratemporal fossae. ${ }^{9.51}$ Although it is possible to remove the nasal and paranasal tumor through a single craniotomy, in our experience such tumors with lateral and medial components benefit from a combined transcranial-endonasal approach. ${ }^{6}$

With the development of endoscopic techniques, the transorbital endoscopic approaches may replace a lateral craniotomy in select circumstances. It is important to notice that transcranial, transorbital, and endoscopic endonasal approaches have different benefits and limitations and should be carefully selected according to the tumor characteristics (Table 3). In the cases described here, hyperostosis of the greater sphenoidal wing due to en plaque meningiomas led to compression of the optic canal, superior orbital fissure, and orbital compartment, resulting in visual deterioration and proptosis. In such cases, symptom relief is the main surgical goal since gross-total resection is not easily achieved with reasonable morbidity through any approach. Debulking of the hyperostosis and orbital decompression were the primary goals of surgery, rather than complete tumor removal, which was the indication for the combined transorbital and endonasal surgery. We were able to remove most of the hyperostotic bone at the orbital roof and sphenoidal wing via the transorbital endoscopic approach; medial orbital decompression was obtained through endoscopic endonasal drilling of the optic canal and removal of the lamina papyracea was removed. As in previously reported studies,,$^{20,44}$ no clinical or neurological complications were associated with the procedure. Postoperative ophthalmological evaluation revealed visual and proptosis improvement. In Case 1, however, it was not possible to achieve complete reduction of the proptosis due to the persistence of soft-tissue enlargement in the orbital apex, consistent with persistent intraconal tumor causing proptosis. Although ocular symmetry was not achieved, significant improvement of orbital compression and visual symptoms were obtained after transorbital surgery, and no further surgical treatment was indicated. Transorbital endoscopic drilling may not be sufficient for all cases, and complementary surgical treatment may be necessary based on the extension of the remaining proptosis and visual symptoms. Development of surgical instruments dedicated to endoscopic transorbital surgery and further experience with this technique will likely improve the results of the procedure. As more experienced is acquired, medial decompression via an endoscopic endonasal approach may become unnecessary in most patients, with the exception of those who present with $360^{\circ}$ involvement of the optic canal. At this point in our surgical experience, medial decompression seems important to improve the surgical corridor for the transorbital endoscopic approach. However, as expertise is gained, a pure transorbital endoscopic approach may be performed for decompression of such lesion.

When compared with previous reports, it is noticeable that the multiportal technique is effective in improving symptoms and obtaining tumor decompression; ${ }^{20,44}$ however, further refinement of this technique is required if practitioners hope to significantly debulk intracranial disease (Table 2). Concerns related to postoperative CSF leakage and orbital damage should also be carefully analyzed. Because of the paucity of data regarding the multiportal approach, it is difficult to draw definitive conclusions regarding those complications. Thus far, however, CSF leaks have not been reported as a major complication..$^{10,20,34,48}$ Fat grafts and fascia lata may be used to occlude dural defects and seem to have higher success rates when used with the multiportal technique than when used 
TABLE 3. Benefits and limitations of transcranial, transorbital, and endoscopic endonasal approaches for treatment of sphenoorbital meningiomas

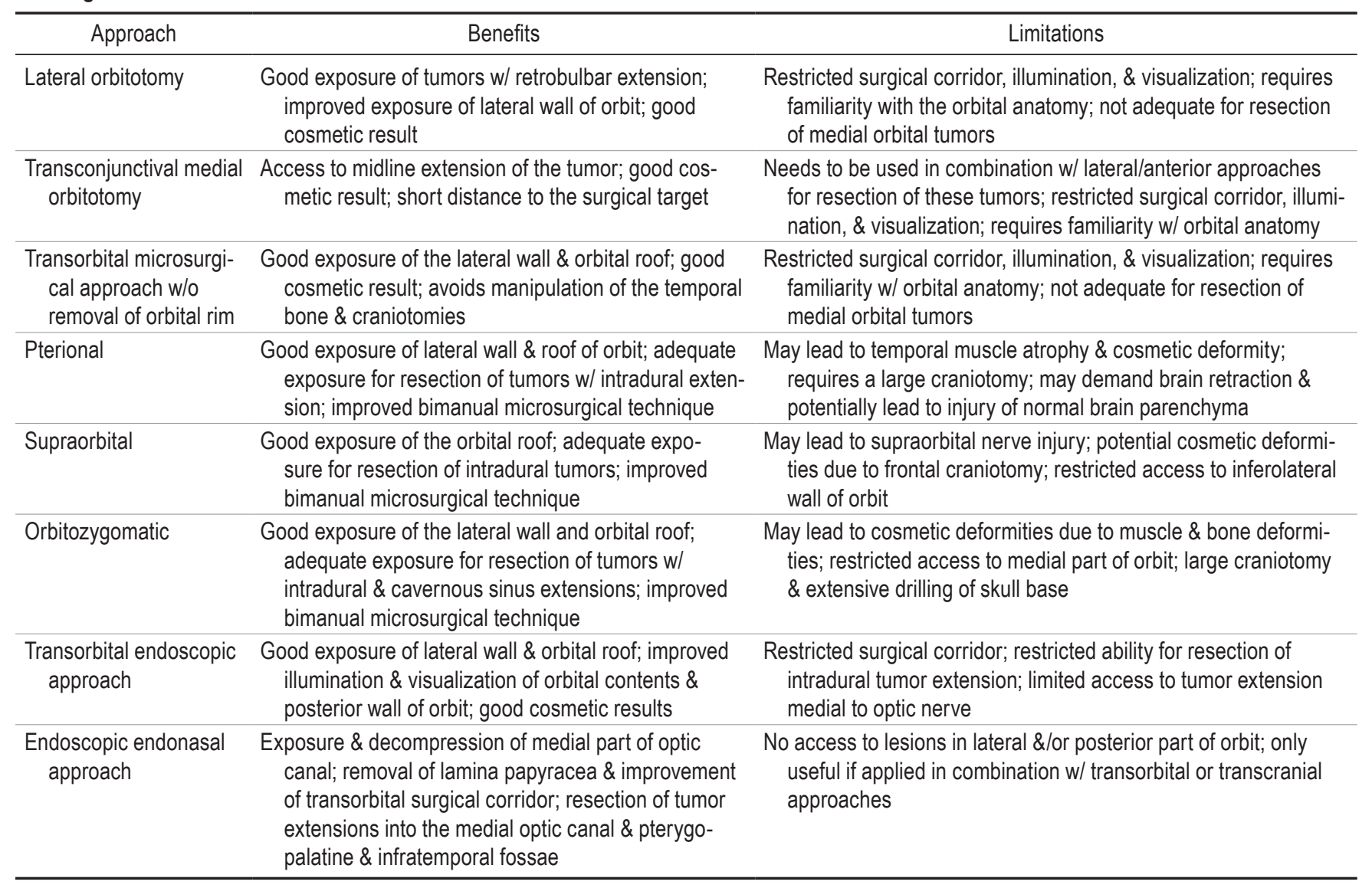

for extended endoscopic approaches. The presence of the orbit and its contents keep the skull base reconstruction in place, which may explain the lower CSF leak rates after transorbital approaches. Orbital damage has not been observed in the current or previous multiportal approach studies. ${ }^{10,20,48}$ Collaboration with oculoplastic surgeons may be useful but is not required once familiarity with the approach is achieved.

\section{Conclusions}

The combined endoscopic transorbital endonasal approach represents a novel, minimally invasive option for the treatment of anterior and middle fossa lesions. The transorbital endoscopic approach provides access to the superolateral orbital region, which makes this an interesting option for the treatment of select SOMs in which hyperostosis and proptosis are the primary issues. In our cases, through a combined approach, subtotal tumor resection and orbital decompression were achieved, leading to improvement in preoperative proptosis and visual deficits, with no postoperative complications. The presence of significant soft-tissue enlargement may be a limitation for successful reduction of the proptosis via an endoscopic transorbital approach. Collaboration among neurosurgeons, otolaryngologists, and oculoplastic surgeons plays a major role in the development of this approach. As with any new surgical technique, more reports and longer follow-up are necessary for a better understanding of its benefits and limitations.

\section{References}

1. Abdel Aziz KM, Bhatia S, Tantawy MH, Sekula R, Keller JT, Froelich S, et al: Minimally invasive transpalpebral "eyelid" approach to the anterior cranial base. Neurosurgery 69 (2 Suppl Operative):ons195-ons207, 2011

2. Alaywan M, Sindou M: Fronto-temporal approach with orbito-zygomatic removal. Surgical anatomy. Acta Neurochir (Wien) 104:79-83, 1990

3. Alqahtani A, Padoan G, Segnini G, Lepera D, Fortunato S, Dallan I, et al: Transorbital transnasal endoscopic combined approach to the anterior and middle skull base: a laboratory investigation. Acta Otorhinolaryngol Ital 35:173-179, 2015

4. Altay T, Patel BC, Couldwell WT: Lateral orbital wall approach to the cavernous sinus. J Neurosurg 116:755-763, 2012

5. Andaluz N, Romano A, Reddy LV, Zuccarello M: Eyelid approach to the anterior cranial base. J Neurosurg 109:341346,2008

6. Attia M, Patel KS, Kandasamy J, Stieg PE, Spinelli HM, Riina HA, et al: Combined cranionasal surgery for sphenoorbital meningiomas invading the paranasal sinuses, pterygopalatine, and infratemporal fossa. World Neurosurg 80:e367-e373, 2013

7. Benedict WL: Surgical treatment of tumors and cysts of the orbit. Am J Ophthalmol 32:763-773, 1949 
8. Berke RN: A modified Kronlein operation. AMA Arch Opthalmol 51:609-632, 1954

9. Bloss HG, Proescholdt MA, Mayer C, Schreyer AG, Brawanski A: Growth pattern analysis of sphenoid wing meningiomas. Acta Neurochir (Wien) 152:99-103, 2010

10. Bly RA, Morton RP, Kim LJ, Moe KS: Tension pneumocephalus after endoscopic sinus surgery: a technical report of multiportal endoscopic skull base repair. Otolaryngol Head Neck Surg 151:1081-1083, 2014

11. Bly RA, Ramakrishna R, Ferreira M, Moe KS: Lateral transorbital neuroendoscopic approach to the lateral cavernous sinus. J Neurol Surg B Skull Base 75:11-17, 2014

12. Cannon PS, Rutherford SA, Richardson PL, King A, Leatherbarrow B: The surgical management and outcomes for spheno-orbital meningiomas: a 7-year review of multi-disciplinary practice. Orbit 28:371-376, 2009

13. Cappabianca P, Cavallo LM, Esposito F, De Divitiis O, Messina A, De Divitiis E: Extended endoscopic endonasal approach to the midline skull base: the evolving role of transsphenoidal surgery. Adv Tech Stand Neurosurg 33:151-199, 2008

14. Castelnuovo P, Dallan I, Battaglia P, Bignami M: Endoscopic endonasal skull base surgery: past, present and future. Eur Arch Otorhinolaryngol 267:649-663, 2010

15. Castelnuovo P, Turri-Zanoni M, Battaglia P, Locatelli D, Dallan I: Endoscopic endonasal management of orbital pathologies. Neurosurg Clin N Am 26:463-472, 2015

16. Chen HI, Bohman LE, Loevner LA, Lucas TH: Transorbital endoscopic amygdalohippocampectomy: a feasibility investigation. J Neurosurg 120:1428-1436, 2014

17. Ciporen JN, Moe KS, Ramanathan D, Lopez S, Ledesma E, Rostomily R, et al: Multiportal endoscopic approaches to the central skull base: a cadaveric study. World Neurosurg 73:705-712, 2010

18. Cockerham KP, Bejjani GK, Kennerdell JS, Maroon JC: Surgery for orbital tumors. Part II: transorbital approaches. Neurosurg Focus 10(5):E3, 2001

19. Czirják S, Szeifert GT: Surgical experience with frontolateral keyhole craniotomy through a superciliary skin incision. Neurosurgery 48:145-150, 2001

20. Dallan I, Castelnuovo P, Locatelli D, Turri-Zanoni M, AlQahtani A, Battaglia P, et al: Multiportal combined transorbital transnasal endoscopic approach for the management of selected skull base lesions: preliminary experience. World Neurosurg 84:97-107, 2015

21. Dallan I, Castelnuovo P, Turri-Zanoni M, Fiacchini G, Locatelli D, Battaglia P, et al: Transorbital endoscopic assisted management of intraorbital lesions: lessons learned from our first 9 cases. Rhinology 54:247-253, 2016

22. Dallan I, Locatelli D, Turri-Zanoni M, Battaglia P, Lepera D, Galante N, et al: Transorbital endoscopic assisted resection of a superior orbital fissure cavernous haemangioma: a technical case report. Eur Arch Otorhinolaryngol 272:3851-3856, 2015

23. Dare AO, Landi MK, Lopes DK, Grand W: Eyebrow incision for combined orbital osteotomy and supraorbital minicraniotomy: application to aneurysms of the anterior circulation. Technical note. J Neurosurg 95:714-718, 2001

24. Frazier CH: I. An approach to the hypophysis through the anterior cranial fossa. Ann Surg 57:145-150, 1913

25. Gaillard S, Lejeune JP, Pellerin P, Pertuzon B, Dhellemmes P, Christiaens JL: [Long-term results of the surgical treatment of spheno-orbital osteomeningioma.] Neurochirurgie 41:391-397, 1995 (Fr)

26. Gaillard S, Pellerin P, Dhellemmes P, Pertuzon B, Lejeune JP, Christiaens JL: Strategy of craniofacial reconstruction after resection of spheno-orbital "en plaque" meningiomas. Plast Reconstr Surg 100:1113-1120, 1997

27. Galbraith JE, Sullivan JH: Decompression of the perioptic meninges for relief of papilledema. Am J Ophthalmol 76:687-692, 1973
28. Hakuba A, Liu S, Nishimura S: The orbitozygomatic infratemporal approach: a new surgical technique. Surg Neurol 26:271-276, 1986

29. Hofstetter CP, Singh A, Anand VK, Kacker A, Schwartz TH: The endoscopic, endonasal, transmaxillary transpterygoid approach to the pterygopalatine fossa, infratemporal fossa, petrous apex, and the Meckel cave. J Neurosurg 113:967-974, 2010

30. Jane JA, Park TS, Pobereskin LH, Winn HR, Butler AB: The supraorbital approach: technical note. Neurosurgery 11:537-542, 1982

31. Jho HD: Orbital roof craniotomy via an eyebrow incision: a simplified anterior skull base approach. Minim Invasive Neurosurg 40:91-97, 1997

32. Kasemsiri P, Carrau RL, Ditzel Filho LF, Prevedello DM, Otto BA, Old M, et al: Advantages and limitations of endoscopic endonasal approaches to the skull base. World Neurosurg 82 (6 Suppl):S12-S21, 2014

33. Kennerdell JS, Maroon JC: Microsurgical approach to intraorbital tumors. Technique and instrumentation. Arch Ophthalmol 94:1333-1336, 1976

34. Koutourousiou M, Gardner PA, Stefko ST, Paluzzi A, Fernandez-Miranda JC, Snyderman CH, et al: Combined endoscopic endonasal transorbital approach with transconjunctival-medial orbitotomy for excisional biopsy of the optic nerve: technical note. J Neurol Surg Rep 73:52-56, 2012

35. Lew H, Rootman DB, Nassiri N, Goh A, Goldberg RA: Transorbital approach without craniotomy to orbital tumors with extradural intracranial extension. Orbit 33:343-351, 2014

36. Maroon JC, Kennerdell JS: Lateral microsurgical approach to intraorbital tumors. J Neurosurg 44:556-561, 1976

37. Maroon JC, Kennerdell JS, Vidovich DV, Abla A, Sternau L: Recurrent spheno-orbital meningioma. J Neurosurg 80:202208, 1994

38. Mathiesen T, Lindquist C, Kihlström L, Karlsson B: Recurrence of cranial base meningiomas. Neurosurgery 39:2-9, 1996

39. McKinney KA, Snyderman CH, Carrau RL, Germanwala AV, Prevedello DM, Stefko ST, et al: Seeing the light: endoscopic endonasal intraconal orbital tumor surgery. Otolaryngol Head Neck Surg 143:699-701, 2010

40. Mirone G, Chibbaro S, Schiabello L, Tola S, George B: En plaque sphenoid wing meningiomas: recurrence factors and surgical strategy in a series of 71 patients. Neurosurgery 65 (6 Suppl):100-109, 2009

41. Moe KS, Bergeron CM, Ellenbogen RG: Transorbital neuroendoscopic surgery. Neurosurgery 67 (3 Suppl Operative):ons16-ons 28,2010

42. Ohjimi H, Taniguchi Y, Tanahashi S, Era K, Fukushima T: Accessing the orbital roof via an eyelid incision: the transpalpebral approach. Skull Base Surg 10:211-216, 2000

43. Oya S, Sade B, Lee JH: Sphenoorbital meningioma: surgical technique and outcome. J Neurosurg 114:1241-1249, 2011

44. Ramakrishna R, Kim LJ, Bly RA, Moe K, Ferreira M Jr: Transorbital neuroendoscopic surgery for the treatment of skull base lesions. J Clin Neurosci 24:99-104, 2016

45. Raza SM, Quinones-Hinojosa A, Lim M, Boahene KD: The transconjunctival transorbital approach: a keyhole approach to the midline anterior skull base. World Neurosurg 80:864-871, 2013

46. Ringel F, Cedzich C, Schramm J: Microsurgical technique and results of a series of 63 spheno-orbital meningiomas. Neurosurgery 60 (4 Suppl 2):214-222, 2007

47. Rivkin MA, Turtz AR, Morgenstern KE: Transorbital endoscopic removal of posterior lateral orbital mass. Laryngoscope 123:3001-3004, 2013

48. Schaberg M, Murchison AP, Rosen MR, Evans JJ, Bilyk JR: Transorbital and transnasal endoscopic repair of a meningoencephalocele. Orbit 30:221-225, 2011 
49. Schick U, Bleyen J, Bani A, Hassler W: Management of meningiomas en plaque of the sphenoid wing. J Neurosurg 104:208-214, 2006

50. Schwartz TH, Fraser JF, Brown S, Tabaee A, Kacker A, Anand VK: Endoscopic cranial base surgery: classification of operative approaches. Neurosurgery 62:991-1005, 2008

51. Shrivastava RK, Sen C, Costantino PD, Della Rocca R: Sphenoorbital meningiomas: surgical limitations and lessons learned in their long-term management. J Neurosurg 103:491-497, 2005

52. Snyderman CH, Pant H, Carrau RL, Prevedello D, Gardner P, Kassam AB: What are the limits of endoscopic sinus surgery?: the expanded endonasal approach to the skull base. Keio J Med 58:152-160, 2009

53. Sonig A, Nanda A: Transorbital approach to the anterior cranial skull base. World Neurosurg 80:810-812, 2013

54. Yaşargil MG, Antic J, Laciga R, Jain KK, Hodosh RM, Smith RD: Microsurgical pterional approach to aneurysms of the basilar bifurcation. Surg Neurol 6:83-91, 1976

\section{Disclosures}

Dr. Schwartz reports that he has direct stock ownership in Visionsense.

\section{Author Contributions}

Conception and design: Schwartz, Almeida, Anand. Acquisition of data: Almeida, Omay, Shetty, Chen, Ruiz-Treviño, Liang, Levine. Analysis and interpretation of data: Schwartz, Almeida, Omay, Shetty, Chen, Ruiz-Treviño, Liang, Levine. Drafting the article: Schwartz, Almeida, Omay, Shetty, Chen, Ruiz-Treviño, Liang. Critically revising the article: Schwartz, Omay, Anand, Levine. Reviewed submitted version of manuscript: Schwartz, Almeida. Approved the final version of the manuscript on behalf of all authors: Schwartz. Study supervision: Schwartz, Anand.

\section{Supplemental Information}

Videos

Video 1. https://vimeo.com/217504007.

Video 2. https://vimeo.com/217504170.

\section{Correspondence}

Theodore H. Schwartz, Department of Neurosurgery, Weill Cornell Medical College, NewYork-Presbyterian Hospital, 525 East 68th St., Box \#99, New York, NY 10065. email: schwarh@med. cornell.edu. 